\title{
Earth's Annual Global Mean Energy Budget
}

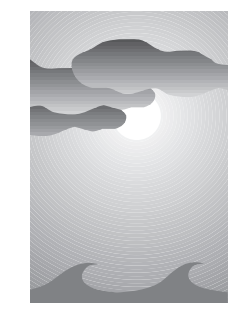

\author{
J. T. Kiehl and Kevin E. Trenberth \\ National Center for Atmospheric Research," Boulder, Colorado
}

\begin{abstract}
The purpose of this paper is to put forward a new estimate, in the context of previous assessments, of the annual global mean energy budget. A description is provided of the source of each component to this budget. The top-ofatmosphere shortwave and longwave flux of energy is constrained by satellite observations. Partitioning of the radiative energy throughout the atmosphere is achieved through the use of detailed radiation models for both the longwave and shortwave spectral regions. Spectral features of shortwave and longwave fluxes at both the top and surface of the earth's system are presented. The longwave radiative forcing of the climate system for both clear $\left(125 \mathrm{~W} \mathrm{~m}^{-2}\right)$ and cloudy $\left(155 \mathrm{~W} \mathrm{~m}^{-2}\right)$ conditions are discussed. The authors find that for the clear sky case the contribution due to water vapor to the total longwave radiative forcing is $75 \mathrm{~W} \mathrm{~m}^{-2}$, while for carbon dioxide it is $32 \mathrm{~W} \mathrm{~m}^{-2}$. Clouds alter these values, and the effects of clouds on both the longwave and shortwave budget are addressed. In particular, the shielding effect by clouds on absorption and emission by water vapor is as large as the direct cloud forcing. Because the net surface heat budget must balance, the radiative fluxes constrain the sum of the sensible and latent heat fluxes, which can also be estimated independently.
\end{abstract}

\section{Introduction}

There is a long history of attempts to construct a global annual mean surface-atmosphere energy budget for the earth. The first such budget was provided by Dines (1917). Over the years improvements in estimating the global annual mean energy budget have resulted from satellite observations. In particular, the narrowed uncertainty in the planetary albedo and outgoing longwave radiation (e.g., Hunt et al. 1986) have greatly improved our understanding of the earth's energy budget. Recently, global satellite-derived estimates of precipitation have also aided (through conservation of moisture) in determining the annual global mean surface latent heat flux. Despite these

\footnotetext{
*The National Center for Atmospheric Research is sponsored by the National Science Foundation.

Corresponding author address: Dr. Jeffrey T. Kiehl, Climate and Global Dynamics Division, National Center for Atmospheric Research, P.O. Box 3000, Boulder, CO 80307-3000.

E-mail: jtkon@ncar.ucar.edu

In final form 5 August 1996.

(C)1997 American Meteorological Society
}

important improvements in our understanding, a number of key terms in the energy budget remain uncertain, in particular, the net absorbed shortwave and longwave surface fluxes.

With regard to the radiative energy component, there is also a wide range in the estimates for the contribution of the individual gaseous absorbers to the radiative forcing of the climate system. Using detailed radiation models for the shortwave and longwave spectral regions, we show what role the various absorbers play in determining the radiative balance of the earth's system and their dependence on the presence or absence of clouds. We also investigate the wavelength dependence of these radiation terms. Constraining the radiation models with satellite observations at the top of the atmosphere, we produce new estimates for the radiative contributions to the earth's energy budget. We also discuss uncertainties resulting from some recent observations of cloud shortwave absorption observations to the global energy budget.

Previous estimates of the global energy budget are reviewed in section 2 , while section 3 presents our model calculations for the longwave and shortwave en- 
ergy budget, section 4 describes the sources employed for the surface latent and sensible heat fluxes, and section 5 discusses the overall global energy budget.

\section{Previous energy budget studies}

The energy budget for the global annual mean is determined by the net radiant flow of energy at different wavelengths through the top of the atmosphere and at the earth's surface. At the top of the atmosphere, net energy input is determined by the incident shortwave radiation from the sun (insolation) minus the reflected shortwave energy. This difference defines the net shortwave radiative flux at the top of the atmosphere. To balance this inflow of shortwave energy, the surface-atmosphere system emits longwave radiation to space. The longwave radiation that reaches the top of the atmosphere results from the absorption and emission of longwave radiation by gases throughout the atmosphere. Thus, little of the longwave energy that escapes to space represents emission directly from the surface. The atmosphere acts as a "blanket" to this radiation, which produces radiative forcing to the climate system. We define the longwave "radiative forcing" of the climate system as the difference between the top of atmosphere longwave flux with and without the greenhouse absorbers. This forcing is not the same as the "greenhouse effect," which is related to the effect absorbers have on the earth's surface temperature. At the earth's surface, the net flux of energy from the surface to the atmosphere is composed of the net (downward minus upward) shortwave flux, the net (upward minus downward) longwave flux, and the fluxes of latent and sensible heat. We consider the long-term equilibrium state of the climate system, which requires the net inflow of energy at both the top of the atmosphere and at the surface to be zero.

Over the past $80 \mathrm{yr}$ there have been a large number of global annual mean energy budget studies. Following the first budget (Dines 1917), there have been a number of other studies (e.g., Hunt et al. 1986). Most of these were severely limited by lack of knowledge concerning the fractional amount of solar radiation reflected by the earth, that is, the planetary albedo. Early estimates of the planetary albedo ranged from $40 \%$ to $50 \%$ (see Hunt et al. 1986 for a review of these early studies). Satellite observations from Nimbus-7 and the Earth Radiation Budget Experiment (ERBE) indicate that the planetary albedo is near $30 \%$, while results from the International Satellite Cloud Climatology Project (ISCCP, Rossow and Zhang 1995) indicate an albedo of $33 \%$. Table 1 presents a summary of recent energy budget studies that have planetary albedos close to the observed value of $30 \%$. Note that we present these budgets in terms of flux of energy $\left(\mathrm{W} \mathrm{m}^{-2}\right)$, rather than the percent of the insolation. We also list in Table 1 the absorbed shortwave flux within the atmosphere. The values from our study are listed in Table 1 and are discussed in more detail in the following sections. There is considerable variation for any given flux of energy. For example, values for the net surface shortwave flux range from 154 to $174 \mathrm{~W} \mathrm{~m}^{-2}$. Similarly, the net surface longwave fluxes differ by $21 \mathrm{~W} \mathrm{~m}^{-2}$, while there is a $10 \mathrm{~W} \mathrm{~m}^{-2}$ spread in both sensible and latent heat fluxes.

The last two rows of Table 1 list "observational" estimates of radiative fluxes. The results from Rossow and Zhang (1995) are based on using satellite data and a radiation model to deduce the surface fluxes. Thus they are not based solely on observations. The only direct radiative surface flux measurements of Ohmura and Gilgen (1993) use the Global Energy Balance Archive to produce their best estimate of the globally averaged net shortwave and longwave surface fluxes. Note that these observations are mainly from land stations. It is clear that the order $20 \mathrm{~W} \mathrm{~m}^{-2}$ spread in shortwave surface flux estimates also applies to these observationally derived estimates of the radiative budget.

\section{Radiative energy budget}

\section{a. Top-of-atmosphere fluxes}

Satellite observations of the top-of-atmosphere earth radiation budget have greatly improved estimates of the global mean energy budget. The ERBE (see Ramanathan et al. 1989) provided nearly 5 yr of continuous data from the mid-1980s. The global annual mean of these data (Kiehl et al. 1994) indicate that the outgoing longwave radiation is $235 \mathrm{~W} \mathrm{~m}^{-2}$, while the mean absorbed shortwave flux is $238 \mathrm{~W} \mathrm{~m}^{-2}$. Thus, the measured top-of-atmosphere energy budget balances to within $3 \mathrm{~W} \mathrm{~m}^{-2}$. A similar net imbalance exists for the long-term Nimbus-7 data as well (Ardanuy et al. 1992).

While ERBE results are believed to be the most definitive on the top-of-atmosphere radiation, they cover only a limited period. Much longer time series are available from Nimbus-7, which allows estimates 
to made of the sampling variability associated with interannual variability (Ardanuy et al. 1992; Kyle et al. 1993). The annual mean net top-of-atmosphere radiation has varied from late 1978 to 1986 by about $1 \mathrm{~W} \mathrm{~m}^{-2}$, part of which could be associated with the buildup of greenhouse gases in the atmosphere, and part of which is probably associated with changes in heat storage within the climate system, such as associated with El Niño events, but is certainly within instrument uncertainties. Barkstrom et al. (1989) made estimates of the uncertainties in ERBE scanner data on a monthly mean regional basis as about $5 \mathrm{~W} \mathrm{~m}^{-2}$ for both the shortwave and longwave radiation. Global-mean average annual radiation was also estimated to have uncertainties of $5 \mathrm{~W} \mathrm{~m}^{-2}$. More comprehensive error estimates were made by Rieland and Raschke (1991). Average root-mean-square (rms) sampling errors due to diurnal sampling for outgoing longwave radiation, absorbed solar radiation, and net radiation were 0.9 , 3.4 , and $3.5 \mathrm{~W} \mathrm{~m}^{-2}$, respectively, for the three satellites combined. However, these numbers increase to about 3,8 , and $9 \mathrm{~W} \mathrm{~m}^{-2}$ for just one satellite. In addition, when other uncertainties from data inversion procedures are included, the final ERBE rms uncertainty estimates are $7.8 \mathrm{~W} \mathrm{~m}^{-2}$ for the three satellite combination versus $11 \mathrm{~W} \mathrm{~m}^{-2}$ for one satellite. Comparisons among radiation results from Nimbus-7, NOAA-9, $N O A A-10$, and $E R B S$ satellites (the latter three were used for ERBE) have been made by Kyle et al. (1990) and Bess and Smith (1993).

Based on these error estimates, we assume that the bulk of the bias in the ERBE imbalance is in the shortwave absorbed flux at the top of the atmosphere, since the retrieval of shortwave flux is more sensitive than the retrieval of longwave flux to the sampling and modeling of the diurnal cycle, surface and cloud inhomogeneities. Therefore, we use the ERBE outgoing longwave flux of $235 \mathrm{~W} \mathrm{~m}^{-2}$ to define the absorbed solar flux. Mean values of the total solar irradiance have varied in different satellite missions from about 1365 to $1373 \mathrm{~W} \mathrm{~m}^{-2}$ (see National Academy of Sciences 1994 for a review; also Ardanuy et al. 1992), and the change with the solar cycle is estimated to be $1.3 \mathrm{~W} \mathrm{~m}^{-2}$. Here we assume a "solar constant" of $1367 \mathrm{~W} \mathrm{~m}^{-2}$ (Hartmann 1994), and because the incoming solar radiation is one-quarter of this, that is, $342 \mathrm{~W} \mathrm{~m}^{-2}$, a planetary albedo of $31 \%$ is implied. 


\section{b. Longwave radiation}

We must rely on model calculations to determine the surface radiative fluxes. As described above, longwave radiation emitted from the surface is absorbed and reemitted by greenhouse gases and clouds throughout the earth's atmosphere. The transfer of longwave radiation depends on both the local temperature of the gaseous absorber and the efficiency of the gases to absorb radiation at a given wavelength. This absorption efficiency varies with wavelength. It is also important to note that different gases can absorb radiation at the same wavelengths; this is called the overlap effect. In the presence of clouds, the transfer of radiation depends on the amount of cloud, the efficiency with which clouds absorb and reemit longwave radiation, that is, the cloud emissivity, and on the cloud top and base temperatures. We employ a narrowband Malkmus model (see Kiehl and Ramanathan 1983; Kiehl 1983) to represent the above physical properties of longwave radiative transfer. This model calculates atmospheric absorption for a prescribed spectral interval. Each of these intervals contains absorption lines due to an atmospheric absorber (water vapor, carbon dioxide, ozone, methane, and nitrous oxide). The line data used to determine the absorption are from a comprehensive spectroscopic database (Rothman et al. 1992). Clouds are assumed to exist in three layers and these layers are assumed to be randomly overlapped.

To calculate the radiative fluxes, it is necessary to specify the vertical distribution of absorbers (gases and clouds) and the temperature. We use the U.S. Standard Atmosphere, 1976 for vertical profiles of temperature, water vapor, and ozone (appendix B of Liou 1992). We assume a $\mathrm{CO}_{2}$ volume mixing ratio of 353 ppmv, a $\mathrm{CH}_{4}$ mixing ratio of $1.72 \mathrm{ppmv}$, and a $\mathrm{N}_{2} \mathrm{O}$ mixing ratio of $0.31 \mathrm{ppmv}$, which are 1990 IPCC concentrations for these gases (Houghton et al. 1990). Although there are a number of other trace gases (e.g., CFC11 and CFC12) that are important to climate change research, the focus of this study is to consider the energy budget for the present atmosphere to within a few $\mathrm{W} \mathrm{m}^{-2}$; hence we neglect gases that contribute less than $1 \mathrm{~W} \mathrm{~m}^{-2}$ to the radiative budget. We also neglect the longwave effect of aerosols based on the work of Coakley et al. (1983).

The ERBE data imply a global mean clear sky outgoing longwave flux of nearly $265 \mathrm{~W} \mathrm{~m}^{-2}$. This observation can be used to check the consistency of the assumed profile and the radiation model. Using the U.S. Standard Atmosphere, 1976 profile in the narrowband model yields a flux of $262 \mathrm{~W} \mathrm{~m}^{-2}$, surprisingly close to the observed flux. We reduce the standard atmosphere tropospheric specific humidity profile by $12 \%$ to ensure agreement between the model and observed global mean clear sky flux. The need to adjust the water vapor profile may be due in part to a bias in the longwave clear sky ERBE data (see Hartmann and Doelling 1991; Kiehl and Briegleb 1992). To obtain the cloudy sky top-of-atmosphere flux of $235 \mathrm{~W} \mathrm{~m}^{-2}$, three levels of cloud are introduced into the model. A low cloud layer between 1 and $2 \mathrm{~km}$ with fractional area of $49 \%$, a midlevel cloud cover of fractional amount of $6 \%$ between 5 and $6 \mathrm{~km}$, and a high cloud amount of $20 \%$ between 10 and $11 \mathrm{~km}$. This assumes that random overlap implies a total cloud cover of $62 \%$, in agreement with the ISCCP (Rossow et al. 1993). The emissivity of the low and midlevel clouds is assumed to be 1 , while for the high-level cloud the emissivity is set to 0.6 . Using the above vertical profiles of absorbers, temperature, and cloud properties ensures a top-ofatmosphere broadband radiative budget that agrees with the global mean ERBE data. We have carried out a sensitivity analysis of our model to the assumed cloud fraction in the three layers. We sequentially increased low, middle, and high cloud amounts by $2 \%$, while keeping the total cloud amount the same. The fluxes at the top-of-the-atmosphere and surface changed by less than $2 \mathrm{~W} \mathrm{~m}^{-2}$, indicating our results are insensitive to the exact cloud fraction in any layer as long as the total cloud is constrained to remain fixed. Note that we are using a single column model to represent the average flux conditions of the atmosphere. This differs from calculating a global distribution of fluxes and then averaging these to obtain a global radiative budget, and it partially accounts for the need to adjust the water vapor profile and cloud properties. To test the importance of using a one-dimensional model, we have compared our radiative fluxes to results from the National Center for Atmospheric Research (NCAR) CCM3 (Kiehl et al. 1996), a three-dimensional climate model that actually calculates fluxes at each grid point on the globe. The globally averaged top-ofatmosphere fluxes from this model are in excellent agreement with ERBE. If we compare the globally averaged surface radiative fluxes from the threedimensional climate model (which were not tuned in any way) with our one-dimensional results, we find agreement to less than $5 \mathrm{~W} \mathrm{~m}^{-2}$. This implies that constraining the one-dimensional model at the top of the atmosphere with ERBE observations places a very strong constraint on the surface radiative fluxes. 
The broadband longwave budget of the atmosphere is given in Table 2; it is listed for clear and cloudy sky conditions. The longwave cloud forcing, clear minus cloudy sky flux, is $30 \mathrm{~W} \mathrm{~m}^{-2}$, which agrees closely with the annual mean ERBE value, as it should because both clear and cloudy sky top-ofatmosphere fluxes are tuned to the ERBE data. The downward flux at the surface depends strongly on the presence of clouds. For the clear sky case the downward emission from the atmosphere to the surface is $278 \mathrm{~W} \mathrm{~m}^{-2}$, while for the cloudy sky case it increases by $46 \mathrm{~W} \mathrm{~m}^{-2}$. This is mainly due to blackbody emission from the low cloud base, and it indicates why it is so difficult to retrieve a longwave surface flux from satellite observations. Due to the strong dependence of net longwave surface flux on cloud-base height and low cloud amount, this term in the surface energy budget must be considered highly uncertain and no doubt explains much of the large variation in the budgets listed in Table 1.

Figure 1 shows upward longwave spectral emission from the earth's surface and at the top of the atmosphere for the cloudy sky case. Thus, integration of these fluxes over wavelength yields the broadband fluxes listed in Table 2. Emission from the surface is assumed to follow Planck's function, assuming a surface emissivity of 1. Globally, variations in surface emissivity can lead to variations in the net longwave flux of less than $5 \mathrm{~W} \mathrm{~m}^{-2}$ (Briegleb 1992). Atmospheric absorption and emission by various gaseous constituents $\left(\mathrm{H}_{2} \mathrm{O}, \mathrm{CO}_{2}, \mathrm{O}_{3}, \mathrm{CH}_{4}\right.$, and $\left.\mathrm{N}_{2} \mathrm{O}\right)$ and clouds leads to the spectral emission at the top of the atmosphere. The largest emission occurs between 8 and $12 \mu \mathrm{m}$ (the so-called atmospheric window). The difference between the surface emission and the top-of-atmosphere emission defines the longwave radiative forcing (Fig. 2), which clearly illustrates that strong atmospheric absorption occurs at $15 \mu \mathrm{m}$ by carbon dioxide and $9 \mu \mathrm{m}$ by ozone, while the effects of water vapor are distributed throughout all wavelengths. Note that the radiative forcing centered at $15 \mu \mathrm{m}$ extends from 12 to $18 \mu \mathrm{m}$, owing to numerous absorp-

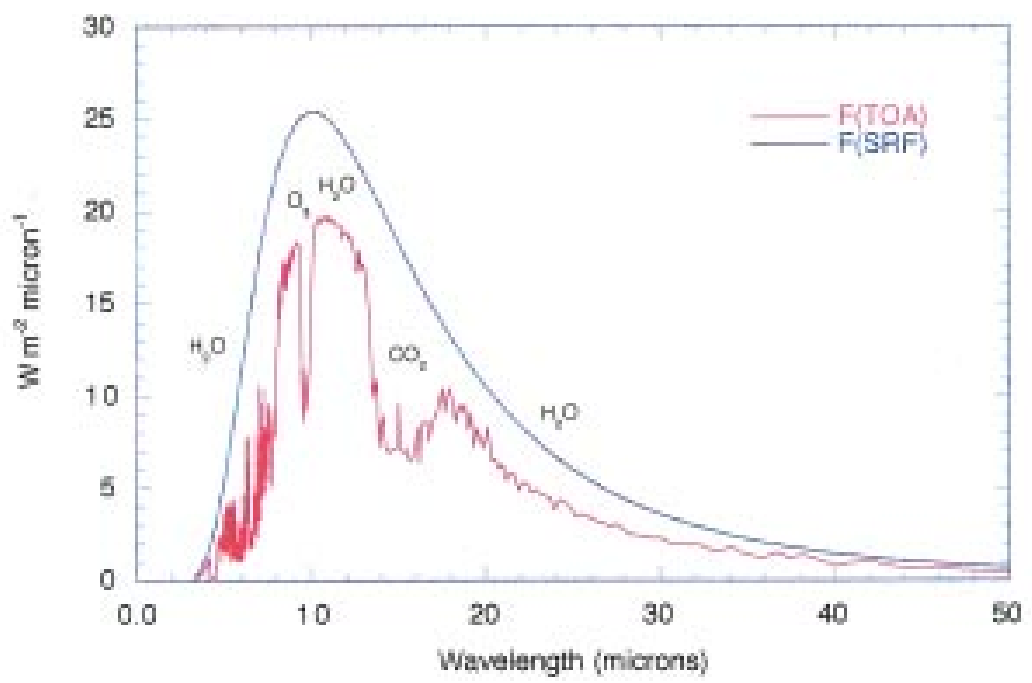

FIG. 1. Surface (blue) and top-of-atmosphere (red) upward longwave flux (W $\mathrm{m}^{-2} \mu \mathrm{m}^{-1}$ ) for global cloudy conditions. Various gases contributing to the absorption and emission of longwave radiation are denoted. 


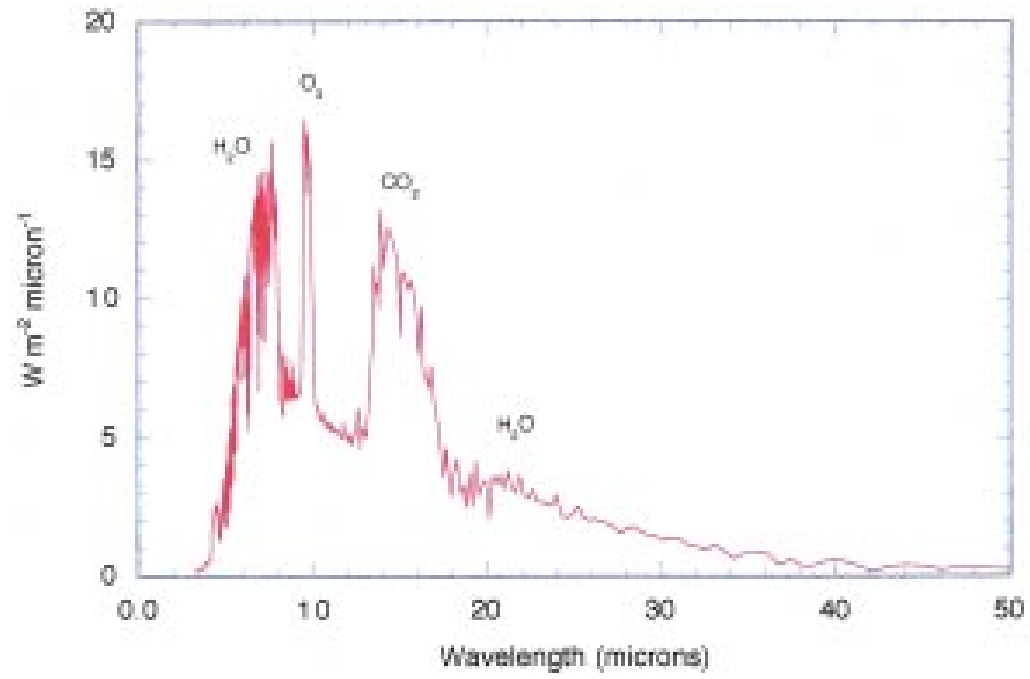

FIG. 2. The radiative forcing ( $\mathrm{W} \mathrm{m}^{-2} \mu \mathrm{m}^{-1}$ ), difference between surface and top-of-atmosphere emission shown in Fig. 1. Various gas absorbers are denoted. tions for each absorber. Because there is strong overlap between clouds and water vapor, the radiative forcing of water vapor is significantly different $\left(22 \mathrm{~W} \mathrm{~m}^{-2}\right)$ between clear and cloudy conditions. The longwave radiative forcing by other gases is less affected by the presence of clouds, but cloud influence is still important since the total radiative forcing for clear and cloudy conditions differs by $39 \mathrm{~W} \mathrm{~m}^{-2}$, a value that is as large as the longwave cloud forcing. Thus, clouds have a direct effect on the longwave flux escaping to space due to their absorption and emission, and they have an indirect effect on the flux by shielding absorption and emission by gases (mainly water vapor). Our cloudy radiative forcing calculations are in good agreement with the overlap between absorption due to water vapor and liquid water in clouds. This overlap is apparent when we consider the spectral distribution of the longwave cloud forcing (Fig. 3). Note that the largest effect of clouds on the outgoing longwave flux is in the atmospheric window $(8-12 \mu \mathrm{m})$.

Of this $125 \mathrm{~W} \mathrm{~m}^{-2}$ clear sky greenhouse effect, we can ask, what is the relative contribution of each atmospheric absorber? A detailed answer to this question is complicated by the overlap among individual gaseous absorption features.

We calculate the longwave radiative forcing of a given gas by sequentially removing atmospheric absorbers from the radiation model. We perform these calculations for clear and cloudy sky conditions to illustrate the role of clouds to a given absorber for the total radiative forcing. Table 3 lists the individual contribution of each absorber to the total clear sky radiative forcing.

For clear skies, water vapor is the most important greenhouse gas, accounting for $60 \%$ of the total. The second most important greenhouse gas is $\mathrm{CO}_{2}$, which contributes $32 \mathrm{~W} \mathrm{~m}^{-2}$ in agreement with Charnock and Shine (1993) but differing from Kandel's (1993) estimate of $50 \mathrm{~W} \mathrm{~m}^{-2}$. The results in the column for combined effects were obtained by splitting the overlap effects among the gases. This is approximate but enables us to arrive at representative percent contribu-

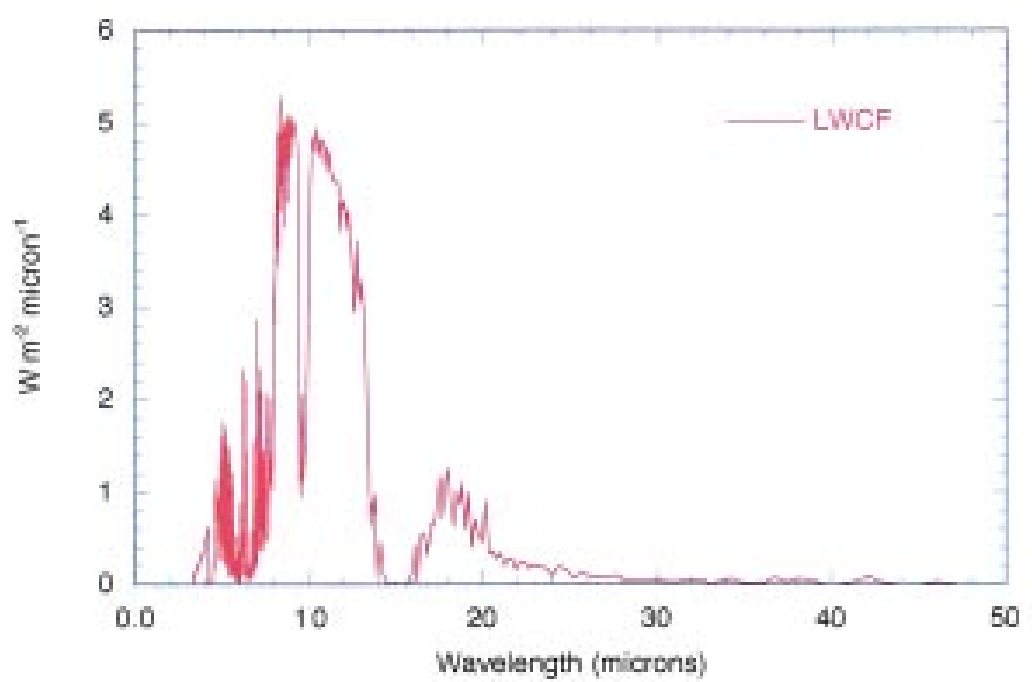

FIG. 3. Longwave cloud forcing ( $\mathrm{W} \mathrm{m}^{-2} \mu \mathrm{m}^{-1}$ ), difference between top-ofatmosphere clear and cloudy outgoing longwave flux. 
by clouds is much greater than molecular (Rayleigh) scattering.

We do not explicitly include the effects of aerosols in the shortwave budget calculations because aerosol optical properties vary greatly due to chemical composition. Thus it is problematic to include them in a global budget. Coakley et al. (1983) have carried out calculations that include various aerosol types over land and ocean, with a global aerosol optical depth of 0.12 . Averaging their results over clear and cloudy conditions and over land and ocean indicates that aerosols decrease the net absorbed shortwave flux at the top of the atmosphere by $-3 \mathrm{~W} \mathrm{~m}^{-2}$, while absorption within the atmosphere is less than $1 \mathrm{~W} \mathrm{~m}^{-2}$. We assume that our final shortwave budget implicitly includes a $3 \mathrm{~W} \mathrm{~m}^{-2}$ loss by aerosols.

For the shortwave spectral region, we employ a detailed adding-doubling model to determine the fluxes in the model atmosphere. The model includes the absorbing effects of $\mathrm{H}_{2} \mathrm{O}, \mathrm{CO}_{2}, \mathrm{O}_{3}$, and $\mathrm{O}_{2}$; atmospheric properties are the same as the longwave case. Cloud heights and amounts are also identical to the longwave cloudy case. For the shortwave calculations we also specify cloud liquid water paths: low cloud, $36 \mathrm{~g} \mathrm{~m}^{-2}$; midcloud, $20 \mathrm{~g} \mathrm{~m}^{-2}$; and high cloud, $9 \mathrm{~g} \mathrm{~m}^{-2}$. A $10-\mu \mathrm{m}$ effective cloud drop radius was assumed for all clouds. Cloud optical properties are calculated from Mie theory (the solution of Maxwell's equations for spherical particles). The above cloud properties are used to assure that the topof-atmosphere absorbed shortwave flux is $235 \mathrm{~W} \mathrm{~m}^{-2}$, which balances the outgoing longwave flux.

Figure 4 shows the spectral distribution of the global annual diurnal mean incoming shortwave radiation at the top of the atmosphere. Also shown is the downward shortwave flux that reaches the surface. The spectral features denoted in Fig. 4 are due to absorption by clouds, water vapor, carbon dioxide, ozone, and oxygen. Features in the nearinfrared (wavelengths beyond $0.9 \mu \mathrm{m}$ ) are due mainly to absorption by water vapor. The spectral distribution of the net top-of-atmosphere shortwave absorbed flux for clear and cloudy conditions (Fig. 5) reveal the absorption peaks of the various gases. Note that in regions where there is strong absorption by water vapor or oxygen, cloud effects are small. It is in the atmospheric window regions where clouds have the largest impact on reducing the absorbed shortwave flux in the climate system. The net absorbed shortwave flux at the earth's surface is $168 \mathrm{~W} \mathrm{~m}^{-2}$, while the atmosphere absorbs $67 \mathrm{~W} \mathrm{~m}^{-2}$.

The contribution of each gas absorber to the total atmospheric absorption is given in Table 4. For cloudy conditions, water vapor accounts for nearly half of the

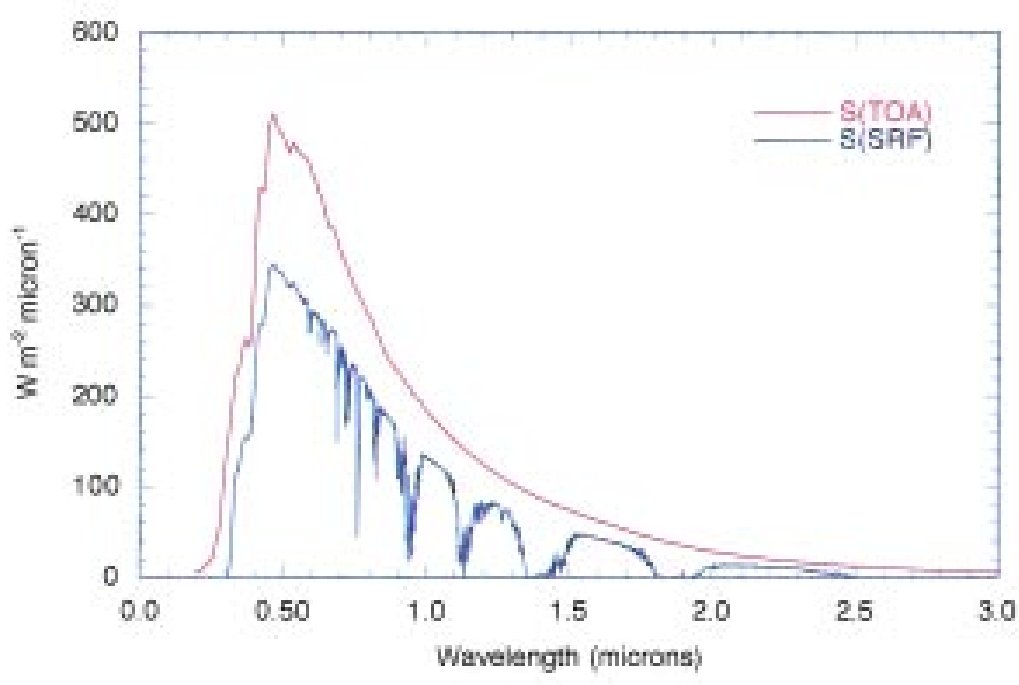

FIG. 4. Downward shortwave flux $\left(\mathrm{W} \mathrm{m}^{-2} \mu \mathrm{m}^{-1}\right)$ at the top of atmosphere (red) and at the surface (blue) for cloudy conditions. 


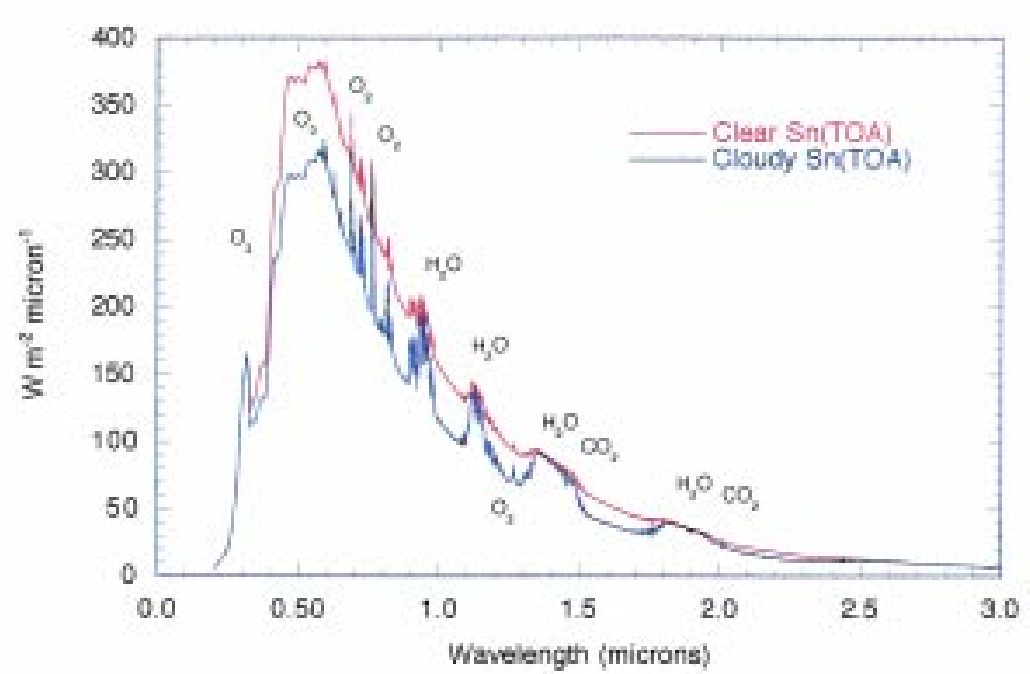

FIG. 5. Net absorbed shortwave flux $\left(\mathrm{W} \mathrm{m}^{-2} \mu \mathrm{m}^{-1}\right)$ at the top of the atmosphere for clear (red) and cloudy (blue) sky conditions. Various gas absorbers are denoted.

total atmospheric absorption, while the second most important absorber is ozone; the contribution by carbon dioxide is small. The other contributor to the total absorption is clouds $\left(7 \mathrm{~W} \mathrm{~m}^{-2}\right)$. The effects of clouds in the top-of-atmosphere shortwave flux can be defined in terms of shortwave cloud forcing, which is the difference between the clear and cloudy net fluxes shown in Fig. 5. Figure 6 shows the spectral distribution of the global mean shortwave cloud forcing. The largest forcing is in the visible part of the spectrum. The total shortwave cloud forcing is $-50 \mathrm{~W} \mathrm{~m}^{-2}$. Thus, combining shortwave and longwave contributions, the net global effect of clouds in our current climate, as also determined by space-based measurements, is a net cooling of the system of

Table 4. Contribution of individual gases to shortwave absorption within the atmosphere. Fluxes are in $\mathrm{W} \mathrm{m}^{-2}$.

\begin{tabular}{lcc}
\hline \multicolumn{1}{c}{ Gas } & Clear sky & Cloudy sky \\
\hline $\mathrm{H}_{2} \mathrm{O}$ & 43 & 38 \\
$\mathrm{CO}_{2}$ & 1 & 0 \\
$\mathrm{O}_{3}$ & 14 & 15 \\
$\mathrm{O}_{2}$ & 2 & 2 \\
\hline Overlap effects & 0 & 12 \\
\hline Total & $\mathbf{6 0}$ & $\mathbf{6 7}$ \\
\hline
\end{tabular}

$-20 \mathrm{~W} \mathrm{~m}^{-2}$. For ERBE the net cloud radiative forcing is estimated as $-19 \mathrm{~W} \mathrm{~m}^{-2}$ (Kiehl et al. 1994) and for Nimbus-7 the value is $-27 \mathrm{~W} \mathrm{~m}^{-2}$ (Ardanuy et al. 1991).

Our surface shortwave absorbed flux of $168 \mathrm{~W} \mathrm{~m}^{-2}$ agrees quite well with the majority of values near $170 \mathrm{~W} \mathrm{~m}^{-2}$ in Table 1. Recently, results from three observational studies (Cess et al. 1995; Ramanathan et al. 1995; Pilewskie and Valero 1995) suggest that clouds may absorb significantly more shortwave radiation than is accounted for in model calculations (such as the models employed in the present study). These results suggest that the cloudy sky absorption may be approximately 20 $25 \mathrm{~W} \mathrm{~m}^{-2}$ greater than models predict. Thus, based on these results, the net shortwave absorption at the surface would be closer to $150 \mathrm{~W} \mathrm{~m}^{-2}$, while the atmospheric absorption would be increased to $85 \mathrm{~W} \mathrm{~m}^{-2}$. It is interesting to note that four of the previous global energy budgets listed in Table 1 (Budyko, Schneider, Liou, and MacCracken) actually coincide with this view. The only observationally based estimate of the global net shortwave flux, by Ohmura and Gilgen (1993), is also indicative of larger atmospheric absorption than existing model calculations. These results suggest an uncertainty of 20-25 W m ${ }^{-2}$ in the current estimates of the shortwave radiative budget. We provide our overall budget (see below) based on the traditional model assumptions. Until these discrepancies are resolved, we should remain open to the possibility that the atmospheric absorption may be greater than the traditional estimates.

\section{Turbulent surface fluxes}

The remaining fluxes required to close the surface energy budget represent turbulent exchanges of sensible heat and latent heat between the surface and the atmosphere. From conservation of water mass the latent heat flux is equal to the global mean rate of precipitation.

Legates (1995) reviews estimates of global mean precipitation after 1960 and values range from 784 to $1123 \mathrm{~mm} \mathrm{yr}^{-1}$, although most credible values occur after about 1975 and range from 966 to $1041 \mathrm{~mm} \mathrm{yr}^{-1}$, or from 2.6 to $3.1 \mathrm{~mm} \mathrm{day}^{-1}$. The highest values come from Legates and Willmott (1990) and include a "bias adjustment" to allow for undercatch in rain and snow 
gauges. Over land, Legates (1995) shows reasonably good agreement among several different sources with annual mean rainfall rates averaging 2.8-3.0 mm day ${ }^{-1}$. The greatest uncertainties are over ocean. For example, the Legates and Willmott climatology has some unrealistic features in the Pacific intertropical convergence zone compared to patterns of rainfall from satellite estimates (e.g., Arkin and Meisner 1987), even if there are questions about the satellitebased estimates (Arkin and Xie 1994). The most comprehensive estimates in recent times are from the Global Precipitation Climatology Project, and we have computed monthly mean global mean precipitation rates for July 1987-December 1988 from the preliminary dataset. Values vary from $2.46 \mathrm{~mm} \mathrm{day}^{-1}$ for December 1987 to $2.90 \mathrm{~mm} \mathrm{day}^{-1}$ for July 1987 with an overall mean for the 18 months of $2.69 \mathrm{~mm}^{-1 a y^{-1}}$ (984 $\mathrm{mm} \mathrm{yr}^{-1}$ ), implying the $78 \mathrm{~W} \mathrm{~m}^{-2}$ latent heat flux used in our energy budget estimate. The latter is very close to $1 \mathrm{~m} \mathrm{yr}^{-1}$, which is a widely accepted approximation for the observed rate. The value for the latent heat flux is identical to that determined by Sellers (1965) and is also close to a number of the estimates listed in Table 1. Gleckler and Weare (1995) estimate zonal mean errors in bulk latent heat fluxes of at least $\pm 25 \mathrm{~W} \mathrm{~m}^{-2}$, and a large portion of this is likely to be systematic (arising from the exchange coefficient, and biases in surface wind speed, moisture gradients, and sea surface and air temperatures).

The remaining heat flux into the atmosphere from sensible heat is deduced as a residual from the condition of the global energy balance at the surface,

$$
\mathrm{SW}-\mathrm{LW}-\mathrm{LH}-\mathrm{SH}=0 .
$$

Employing the surface budget values described above of a net shortwave flux of $168 \mathrm{~W} \mathrm{~m}^{-2}$, a net longwave flux of $66 \mathrm{~W} \mathrm{~m}^{-2}$, and a latent heat flux of $78 \mathrm{~W} \mathrm{~m}^{-2}$ implies a sensible heat flux of $24 \mathrm{~W} \mathrm{~m}^{-2}$. Sensible heat flux can also be determined from a bulk formula (e.g., Sellers 1965; Budyko 1982) and these values can be checked with more recent estimates over the oceans using the Comprehensive Ocean-Atmosphere Data Set (COADS) as analyzed by da Silva and Levitus (1994). The global ocean and annual mean sensible heat flux from the latter is $10 \mathrm{~W} \mathrm{~m}^{-2}$ versus $11 \mathrm{~W} \mathrm{~m}^{-2}$ from both Budyko and Sellers.
For the global and annual mean (including land) Budyko gives $17 \mathrm{~W} \mathrm{~m}^{-2}$ and Sellers gives $18 \mathrm{~W} \mathrm{~m}^{-2}$. However, the uncertainties in these values are considerable. Gleckler and Weare (1995) estimate errors in the bulk flux sensible heat of $\pm 5-10 \mathrm{~W} \mathrm{~m}^{-2}$ with systematic errors of order $5 \mathrm{~W} \mathrm{~m}^{-2}$.

\section{Summary and discussion}

The new estimate of the annual global energy budget is shown in Fig. 7, where the sources of the individual components are discussed in sections 2,3 , and 4. The budget in Fig. 7 is based on the results that do not include any additional atmospheric solar absorption that may be present, as discussed in section 3 . The budget is coincidentally close to that provided by Henderson-Sellers and Robinson (1986) (to within $1 \mathrm{~W} \mathrm{~m}^{-2}$ ). If the new estimates for shortwave cloud absorption are employed, it would imply less solar radiation reaching the surface similar to the budget of Liou (1992) in Table 1.

For the outgoing fluxes, the surface infrared radiation of $390 \mathrm{~W} \mathrm{~m}^{-2}$ corresponds to a blackbody emission at $15^{\circ} \mathrm{C}$. Some of the radiation leaving the atmosphere originates near the earth's surface and is transmitted relatively unimpeded through the atmosphere; this is the radiation from areas where is no cloud and that is present in the part of the spectrum known as the atmospheric window, taken here to be the wavelengths $8-12 \mu \mathrm{m}$ (Fig. 7). The estimate of the amount leaving via the atmospheric window is somewhat ad hoc. In the clear sky case, the radiation in the

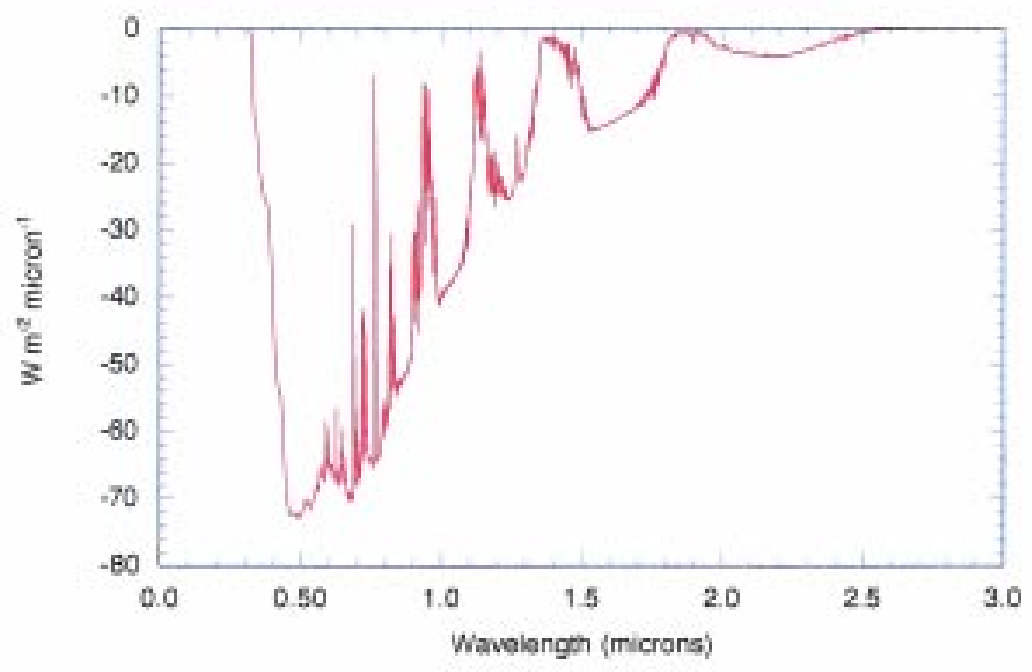

FIG. 6. Shortwave cloud forcing ( $\mathrm{W} \mathrm{m}^{-2} \mu \mathrm{m}^{-1}$ ), difference between top-ofatmosphere cloudy and clear net absorbed flux. 


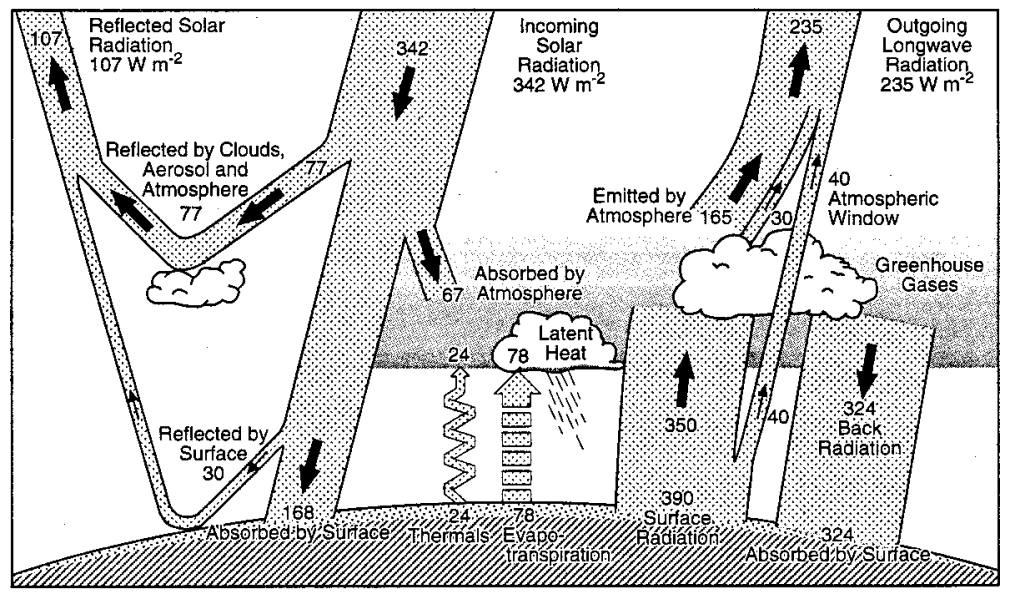

FIG. 7. The earth's annual global mean energy budget based on the present study. Units are $\mathrm{W} \mathrm{m}^{-2}$. models to study the broadband and spectral characteristics of these energy fluxes and we employed recent satellite data to constrain both these radiative fluxes and the global latent heat flux (through the global rate of precipitation). Thus we have described in some detail the source of our estimates for the energy budget.

We also have investigated the longwave radiative forcing of the earth's climate system and considered the contribution to the total radiative forcing by individual absorbers. For the clear sky, water vapor contributes to $60 \%$ of the total radiative forcing, while carbon dioxide contributes $26 \%$ to the clear sky radiative forcing. In discussing increases in greenhouse gases and their impact on

window amounts to $99 \mathrm{~W} \mathrm{~m}^{-2}$, while in the cloudy case the amount decreases to $80 \mathrm{~W} \mathrm{~m}^{-2}$, showing that there is considerable absorption and re-emission at wavelengths in the so-called window by clouds. The value assigned in Fig. 7 of $40 \mathrm{~W} \mathrm{~m}^{-2}$ is simply $38 \%$ of the clear sky case, corresponding to the observed cloudiness of about $62 \%$. This emphasizes that very little radiation is actually transmitted directly to space as though the atmosphere were transparent. The atmospheric emitted radiation is apportioned into two parts to show the LWCF of $30 \mathrm{~W} \mathrm{~m}^{-2}$.

The values put forward in Fig. 7 are reasonable but clearly not exact. The purpose of this paper is not so much to present definitive values, but to discuss how they were obtained and give some sense of the uncertainties and issues in determining the numbers. Several quantities in Fig. 7 are not adequately measured to pin them down as much as desirable, and the global climate models are not yet good enough to justify refining the estimates here, which are based on a much simpler but appropriately tuned and observationally constrained radiation model. By putting all the estimates together, however, the fact that the total heat budget at both the surface and the top of the atmosphere has to balance and all the components add up is a considerable constraint and lends some confidence to the values assigned. Regardless of the errors assigned to each component, the fact that the components sum to zero means some errors must cancel.

We have reviewed the earth's global annual mean energy budget, and the individual components of the energy budget have been described in detail. For the radiative budget we used detailed radiative transfer climate change, the dominant contribution of water vapor to the current greenhouse effect is often overlooked. We have also demonstrated that the presence of clouds in the atmosphere complicates these percent contributions due to the strong wavelength overlap between absorption by water vapor and liquid.

The uncertainties in the annual global mean energy budget at both the top of the atmosphere and the surface highlight areas where improved measurements are needed to improve understanding and models. By far the largest sources of uncertainty appear in the absorbed shortwave radiation. Surface latent heat fluxes are quite poorly known locally, but only the systematic biases contribute to global and annual errors. Moreover, they can be estimated in several ways by using the constraint of the balance of the hydrologic cycle. By discussing the uncertainties in the various estimates of the heat budget components, we hope to focus attention on the need for improvements and, in this way, introduce strong observationally based constraints for global climate models.

Acknowledgments. We thank B. Briegleb for performing the shortwave radiation calculations for us. This research was supported in part (KET) by the NOAA Climate and Global Change Program under Grant NA56GP0247 and by NASA under NASA Order W-18 077, and (JTK) by the DOE Atmospheric Radiation Measurements Program Grant DE-FG05-93ER61376.

\section{References}

Ardanuy, P. E., L. L. Stowe, and A. Gruber, 1991: Shortwave, longwave, and net cloud-radiative forcing as determined from Nimbus-7 observations. J. Geophys. Res., 96, 18 537-18 549. 
- , H. L. Kyle, and D. Hoyt, 1992: Global relationships among the earth's radiation budget, cloudiness, volcanic aerosols and surface temperature. J. Climate, 5, 1120-1139.

Arkin, P. A., and B. N. Meisner, 1987: The relationship between large-scale convective rainfall and cold cloud cover over the western hemisphere during 1982-84. Mon. Wea. Rev., 115, 51-74.

— Project: First algorithm intercomparison project. Bull. Amer. Meteor. Soc., 75, 401-420.

Barkstrom, B., E. Harrison, G. Smith, R. Green, J. Kibler, R. Cess, and the ERBE Science Team, 1989: Earth Radiation Budget Experiment (ERBE) archival and April 1985 results. Bull. Amer. Meteor. Soc., 70, 1254-1262.

Bess, T. D., and G. L. Smith, 1993: Earth radiation budget: Results of outgoing longwave radiation from Nimbus-7, NOAA9, and ERBS satellites. J. Appl. Meteor., 32, 813-824.

Briegleb, B. P., 1992: Longwave band model for thermal radiation in climate studies. J. Geophys. Res., 97, 11 475-11 485.

Budyko, M. I., 1982: The Earth's Climate: Past and Future. Academic Press, 307 pp.

Cess, R. D., and Coauthors, 1995: Absorption of solar radiation by clouds: Observations versus models. Science, 267, 496-499.

Charnock, H., and K. P. Shine, 1993: $\mathrm{CO}_{2}$ 's greenhouse contribution debated. Physics Today, 46, December, 66.

Coakley, J. A., R. D. Cess, and F. B. Yurevich, 1983: The effect of tropospheric aerosols on the earth's radiation budget: A parameterization for climate models. J. Atmos. Sci., 40, 116138.

da Silva, A. M. and S. Levitus, 1994: Anomalies of Heat and Momentum Fluxes. Vol. 3, Atlas of Surface Marine Data 1994, U.S. Department Commerce, 413 pp.

Dines, W. H., 1917: The heat balance of the atmosphere. Quart. J. Roy. Meteor. Soc., 43, 151-158.

Gleckler, P. J., and B. C. Weare, 1995: Uncertainties in global ocean surface heat flux climatologies derived from ship observations. PCMDI Rep. 26, 40 pp. [Available from OSTI, P.O. Box 62, Oak Ridge, TN 37831.]

Hartmann, D. L., 1994: Global Physical Climatology. Academic Press, $411 \mathrm{pp}$.

— J. Geophys. Res., 96, 869-891.

Henderson-Sellers, A., and P. J. Robinson, 1986: Contemporary Climatology. John Wiley \& Sons, 439 pp.

Houghten, J. T., G. J. Jenkins, and J. J. Ephraums, Eds.,1990: Climate Change. The IPCC Scientific Assessment. Cambridge University Press, 365 pp.

Hunt, G. E., R. Kandel, and A. T. Mecherikunnel, 1986: A history of presatellite investigations of the earth's radiation budget. Rev. Geophys., 24, 351-356.

Kandel, R. S., 1993: $\mathrm{CO}_{2}$ 's greenhouse contribution debated. Physics Today, 46, December, 66-67.

Kiehl, J. T., 1983: Satellite detection of effects due to increased atmospheric carbon dioxide. Science, 222, 504-506.

_ , and V. Ramanathan, 1983: $\mathrm{CO}_{2}$ radiative parameterization used in climate models: Comparison with narrow band models and with laboratory data. J. Geophys. Res., 88, 5191-5202.

_ , and B. P. Briegleb, 1992: Comparison of the observed and calculated clear sky greenhouse effect: Implications for climate studies. J. Geophys. Res., 97, 10 037-10 049.
— radiation budget of the National Center for Atmospheric Research community climate model CCM2 and comparisons with the Earth Radiation Budget Experiment (ERBE). J. Geophys. Res., 99, 20 815-20 827.

,-- , G. B. Bonan, B. A. Boville, B. P. Briegleb, D. L. Williamson, and P. J. Rasch, 1996: Description of the NCAR Community Climate Model (CCM3). NCAR Tech. Note NCAR/TN-420+STR, 143 pp. [Available from Publications Office of NCAR, P.O. Box 3000, Boulder, CO 80307.]

Kyle, H. L., J. R. Hickey, P. E. Ardunuy, H. Jacobowitz, A. Arking, G. G. Campbell, and T. H. Vonder Haar, 1990: A comparison of two major Earth radiation budget data sets. J. Geophys. Res., 95, 9951-9970.

_ get (ERB) Experiment: 1975 to 1992. Bull. Amer. Meteor. Soc., 74, 815-830.

Legates, D. R., 1995: Global and terrestrial precipitation: A comparative assessment of existing climatologies. Int. J. Climatol., 15, 237-258.

— , and C. J. Willmott, 1990: Mean seasonal and spatial variability in gauge-corrected global precipitation. Int. J. Climatol., 10, 111-127.

Liou, K. N., 1992: Radiation and Cloud Processes in the Atmosphere. Oxford University Press, 487 pp.

MacCracken, M. C., 1985: Carbon dioxide and climate change: Background and overview. Projecting the Climatic Effects of Increasing Carbon Dioxide, M. C. MacCracken and F. M. Luther, Eds., U.S. Department of Energy, 1-23.

National Academy of Sciences, 1975: Understanding Climatic Change: A Program for Action. National Academy Press, 239 pp.

_ 1994: Solar Influences on Global Change. National Academy Press, 162 pp.

Ohmura, A., and H. Gilgen, 1993: Re-evaluation of the global energy balance. Interactions between the Global Climate Subsystems: The Legacy of Hann, Geophys. Monogr., No. 75, Int. Union Geodesy and Geophys., 93-110.

Paltridge, G. W., and C. M. R. Platt, 1976: Radiative Processes in Meteorology and Climatology. Elsevier, $318 \mathrm{pp}$.

Peixoto, J. P., and A. H. Oort, 1992: Physics of Climate. American Institute of Physics, $520 \mathrm{pp}$.

Pilewskie, P., and F. P. J. Valero, 1995: Direct observations of excess solar absorption by clouds. Science, 267, 1626-1629.

Ramanathan, V., 1987: The role of earth radiation budget studies in climate and general circulation research. J. Geophys. Res., 92, 4075-4095.

— tive-convective models. Rev. Geophys. Space Sci., 16, 465-489.

— , R. D. Cess, E. F. Harrison, P. Minnis, B. R. Barkstrom, E. Ahmad, and D. Hartmann, 1989: Cloud radiative forcing and climate: Results from the Earth Radiation Budget Experiment. Science, 243, 57-63.

—, B. Subasilar, G. J. Zhang, W. Conant, R. D. Cess, J. T. Kiehl, H. Grassl, and L. Shi, 1995: Warm pool heat budget and shortwave cloud forcing: A missing physics? Science, 267, 499-503.

Rieland, M. and E. Raschke, 1991: Diurnal variability of the earth radiation budget: Sampling requirements, time integration aspects and error estimates for the Earth Radiation Budget Experiment (ERBE). Theor. Appl. Climatol., 44, 9-24. 
Rossow, W. B., and Y.-C. Zhang, 1995: Calculation of surface and top of atmosphere radiative fluxes from physical quantities based on ISCCP data sets 2. Validation and first results. J. Geophys. Res., 100, 1167-1197.

, A. W. Walker, and L. C. Garder, 1993: Comparison of ISCCP and other cloud amounts. J. Climate, 6, 23942418.
Rothman, L. S., and Coauthors, 1992: The HITRAN molecular database: Editions of 1991 and 1992. J. Quant. Spectrosc. Radiat. Transfer, 48, 469-507.

Schneider, S. H., 1987: Climate Modeling. Sci. Amer., 256 (5), 72-80.

Sellers, W. D., 1965: Physical Climatology. University of Chicago Press, 272 pp.

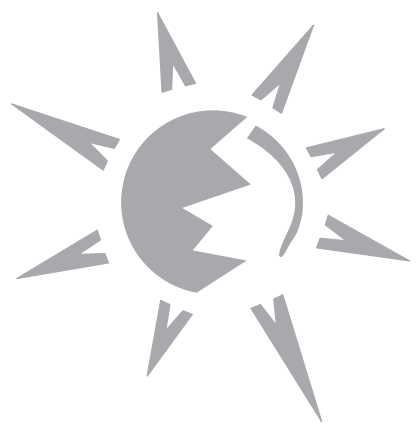

